\title{
Creative Democracy
}

Optimism about democracy is today under a cloud. (LW2: 304)

\section{Unfashionable democracy}

When Dewey published The Public and Its Problems in 1927, democracy had become somewhat of an unfashionable aspiration, with populations in Europe beginning to turn to the extreme Left and Right for their political settlements. In Russia the October Revolution was nearly ten years old, in Italy Mussolini had been in power for three years and in Germany both volumes of Mein Kampf had been published. At home in the United States of America, even the pretence of democracy in the country had come under attack. ${ }^{1}$ The catalyst for this attack on American democracy revolved around the dissipation of post-First World War optimism about reconstructing America in fairer and more just terms. Whilst Progressives put forward ideas for economic justice and fairness, such reforms were 'strangled' by older patterns of thought and behaviour that re-emerged in the climate of revolution (Kloppenberg 1986). The breakdown of this optimism amongst American progressives in turn gave way to the rise of trenchant intellectual critiques of the suitability of democratic government for 1920s America. Conducted by American political scientists and commentators, these critiques of the suitability of democratic government would form what became known as 'democratic realism'. And by the 1930s, the paradigm had become near hegemonic in American social science (Westbrook 1991: 281-6). 
The main charge of democratic realism was that democracy was now unable to provide a stable or efficient government for advanced industrial societies. For democratic realism, the institutions of democratic government, which were based on democracy's core beliefs in the capacity of all people for rational political action and the belief in maximizing civic participation in public life, were in fact counterproductive to good government in industrial societies (Westbrook 1991: 281-2). The main articulation of this position was to be found in the work of Walter Lippmann and his two treatises against standard liberal thought, Public Opinion (1922) and The Phantom Public (1925). Within these works, Lippmann puts forward the idea that America had entered into the Great Society, which made the core beliefs of democracy unrealizable.

The concept of the Great Society, adapted by both Lippmann and later Dewey from Graham Wallas' (1914) book of the same name, was essentially shorthand for the complex industrial and mass consumer society America had become in the aftermath of the First World War. The end of the American Civil War had signalled that America would use its vast reserves of raw materials and land to become a continental nation state with an industrial economy rather than being a decentralized federation of states with a slave-based agrarian economy. ${ }^{2}$ This process had seen America not only master the steam-, coal- and railway-based technologies and industries of the first industrial revolution, but also become the leader of the second industrial revolution of the late nineteenth and early twentieth centuries. This saw the systematic application of science to the industrial process in the new oil-, electricity- and chemicalbased industries of automobiles, synthetic material production and consumer durables (Frieden 2006: 152; Morris 2011: 510; Lind 2012: 5-10). The result was that, as early as 1914, the US economy, in both absolute figures and per capita terms, had overtaken Britain as the biggest economy in the world. By 1919, due in part to the economic consequences of the First World War, US economic output was greater than all of Europe (Kennedy 1987: 242-4). 
Dewey argued that the Great Society's improvements in industrial production, travel and transportation (railways, cars), media (radio, newspapers) and communications (telegraph, telephone) not only eliminated distance as an economic and social factor but also created 'interaction and interdependence' on an unprecedented complex and wide scale (LW2: 307). In industry, for example, the new corporations of 1920s America such as General Motors, Ford and General Electric did not just produce oligopolistic industries but had become vertically integrated entities. Such vertically integrated corporations and the widespread use of electricity, cheaper steel production, the chemical industry and the advent of the assembly line thus delivered mass industrial production. ${ }^{3}$

The move from an agrarian to such an advanced capitalist society had essentially brought about massive changes in the day-to-day life of Americans. The revolution in corporate structure and industrial production, which saw consumer durables such as cars, radios and refrigerators become the driving force of economic growth, had seen a concomitant revolution of mass consumption. And as productivity soared, the prices of consumer durables dropped. Ford's Model T, for example, reduced in price from \$700 (US) in 1910 to \$350 (US) in 1916 and by 1916 it took only six months for the average American to earn enough money to buy one. By 1929, Americans were driving some 26 million cars or trucks. And this is to say nothing of the 20 million phones installed by 1930, new public highways and railway lines, the advent of chain stores and modern advertising, radio set sales, electric stoves and heaters, consumer credit and the fact that by 1924 one could even buy sliced bread (Leuchtenburg 1993: 178-202; Frieden 2006: 62-3, 155-72).

For writers such as Lippmann, the emergence of the Great Society created a far too complex industrial and corporate environment for a normal citizen to exercise rational political judgement about how such a society should be governed. For Lippmann the common citizen was being driven along by industrial innovation and expertise that they could not grasp and was also distracted by mass consumption. As a result, 
modern citizens were incapable of grasping their immediate present, their own interests and essentially living in a world they 'cannot see, [do] not understand and [are] unable to direct' (Lippmann 1925: 4). The democratic goal of maximizing the civic participation of all citizens in public life was thus simply 'bad only in the sense that it is bad for a fat man to try to be a ballet dancer' (Lippmann 1925: 29). The only solution, argued Lippmann, was for normal citizens to give up the concept of selfrule and move towards a system of elitism, whereby experts who are in a position to grasp the complexities of the Great Society would create and enact social policy. In this context, citizens would only play the role of siding with or against different elites, playing no role in policy formation and simply voting for the 'Ins when things are going well and the Outs when things are going badly' (Lippmann 1925: 126).

In Dewey's eyes, the attacks upon democracy by communism, fascism and democratic realism were bound to fail miserably or end up in violence and bloodshed. Quite simply, democratic realism's quasiPlatonism and communism and fascism's authoritarianism, which held experts or rulers as the only ones capable to enact policies that would be wise and beneficial to the common good of society, contradicted the historical record. The emergence and practice of democracy itself had shown that it is only through wide consultation and discussion that wider social needs and common goods are uncovered. As Dewey colourfully put it, the man '.. who wears the shoe knows best that it pinches and where it pinches, even if the expert shoe maker is the best judge of how the trouble is to be remedied' (LW2:364). To subsequently remove the input of the masses and leave government policy to an elite was to create a class closed off from the knowledge of the needs that they were supposed to serve. Dewey therefore feared that rule by an elite group in which the masses could not express their needs would resemble an oligarchy managed in the interests of the few rather than the many. And as Dewey reminded his readers, such fears were not mere abstractions when history patently highlighted how the '.. world has suffered more from leaders and authorities than from the so-called folly of masses' (LW2: 365). ${ }^{4}$ 
The Public and Its Problems is thus best seen as attempting to walk along the path that Dewey believed the far Left and Right in Europe and democratic realism in America shed light upon but refused to travel: the contemporary problem of democracy within the Great Society. Moreover, Dewey sets himself the goal of answering the question that he believed Lippmann and others hastily skimmed over by rendering the masses innately incapable of civic organization: Why is the contemporary public seemingly unable to intelligently perform the tasks that democracy requires of them? To accomplish this, Dewey embarks upon two interrelated tasks within The Public and Its Problems. The first task, which I examine below, involves Dewey reconstructing the concept of democracy as a form of 'creative democracy', simultaneously redefining the political concepts of the 'state', 'public', 'government' and ultimately 'democracy' itself. As I outline in Chapter 2, this task saw Dewey stretch those concepts beyond the remit of the nation state. The second task, which we will discuss in Chapter 3, involves the examination of why the democracy of Dewey's present within the Great Society bore a poor resemblance to his own vision of democracy as a way of life. ${ }^{5}$

\section{Problematic states and their problematic publics: The futility of state theory}

It was Dewey's belief that the meaning of democracy and the justification for its practice had seemingly become lost in the hubris of democratic realism. In the journey to reconstruct and redefine the concept of democracy, Dewey initially returns to another, if not the most, perennial question of political philosophy: What is the origin and nature of the state? In reference to what he believed were prior flawed theories of the state, from the works of Aristotle through to and beyond Hegel, Dewey cautions his readers that the "moment we utter the words "The State" a score of intellectual ghosts rise to obscure our vision' (LW2: 240).

This obfuscation, Dewey contended, arose because theories of the state resorted to mythological 'state-forming forces' or 'political 
instincts' to explain the state and its functions. For example, Aristotle's claim that man by nature is an animal that lives in a state and Social Contract Theory's claim that the state emerges after a fictional state of nature tell us nothing about how actual states come into being or why states take on different forms at different points in history. Such theories merely repackaged the outcome of a given social process (Greek City State/Liberal Democracy) as its cause and reduplicated it in ' ... a so called causal force the effects to be accounted for.' Ultimately, Dewey charged, that such theories hold no more explanatory value than the statement that opium had sleep-inducing effects because of its 'dormative powers' (LW2: 240-1).

Following his dismissal of the explanatory value of prior theories of the state, Dewey begins his own analysis of politics - its institutional forms and practices - from the very empirical starting point he believes the aforementioned theories neglect: the history of human activity and its consequences (LW2: 243). Building upon his prior engagement with Darwin's theory of evolution and the psychology of William James, Dewey puts forward an argument for the social nature of both the self and morality. The foundation of this argument is that like all objects within nature, human beings exist in an environment where 'conjoint, combined, associated action is a universal trait of the behaviour of things' (LW2: 257). What we take to be human nature or what we take to be the human 'self' is said by Dewey not to be an immutable property or instinct which individuals then utilize to interact with their environment, but rather an entity which is produced as the outcome of the interaction of the human organism with its environment. ${ }^{6}$

This interaction of the human organism with its environment takes place through what Dewey denotes as habits, which 'bind us to orderly and established ways of action' (LW2: 335). ${ }^{7}$ In this sense, habits are not simply recurrent or routine ways of behaving but rather acquired predispositions or modes of response, which generate ease, skill and interest when individuals interact with their environment:

For we are given to thinking of a habit as simply a recurrent external mode of action, like smoking or swearing, being neat or negligent 
in clothes and person, taking exercise or playing games. But habit reaches even more significantly down into the very structure of the self; it signifies a building up of and solidifying of certain desires; an increased sensitiveness and responsiveness to certain stimuli, a confirmed or impaired capacity to attend to and think about certain things. Habit covers in other words the very make up of desire, intent, choice, disposition which gives an act its voluntary quality. (LW7: 170-1)

The important point to consider here, however, is that we do not simply create our habits out of thin air, but rather acquire and learn our habits from what Dewey calls 'social customs'. Much like the language we speak, individuals inherit and form their personal moral habits from the uniformities, habits or set ways of conduct of the respective social groups they are born into or are associated with throughout their lives. From birth onwards individuals find that established social customs, which saturate such habits with meaning, are taught and transmitted to them through the associated life they have with other humans (MW14: 43-52). As Dewey points out, the sailor, miner, fisherman and farmer think about their actions, but their thoughts fall within the framework of accustomed occupations and social relations. What an individual actually is as a self - that is, how an individual thinks and acts - is ultimately dependent upon the nature and movement of their associated life (LW5: 275).

These habits and customs are structured through what Dewey calls a society's 'cultural matrix'. 'The idea of a 'cultural matrix' thus corresponds to a society's socio-economic, technological and intellectual (religion/ science/philosophy/politics) practices, which determine the associative relations (occupations, family structures and geographical links) and the meanings (habits/customs) attached to those associated relations by various social groups (LW12: 481-2). As such, a society's cultural matrix provides an:

... inalienable and ineradicable framework of conceptions which is not of our own making, but given to us ready-made by society a whole apparatus of concepts and categories, within which and by 
which individual thinking, however daring and original, is compelled to move. (LW12: 482)

It may be tempting to think from the above that Dewey assigns priority of society over the individual and that the individual is only an expression of society. However, Dewey's point is that the human self is produced through pre-existent associations and the social customs of other humans not society at large (M14: 44, cf. Gouinlock 1972: 105-6). This does not discount that social customs can stretch across society but such a subtle distinction highlights how societies are not uniform but rather pluralistic entities:

Society is one word, but many things. Men associate together in all kinds of ways and for all kinds of purposes. One man is concerned in a multitude of diverse groups, in which his associates may be quite different. It often seems as if they had nothing in common except that they are modes of associated life. Within every larger social organisation there are numerous minor groups; not only political subdivisions but industrial, scientific, religious, associations. There are political parties with differing aims, social sets, cliques, gangs, corporations, partnerships, groups bound closely together by ties of blood, and so in endless variety. In many modern states, and in some ancient, there is great diversity of populations, of varying languages, religions, moral codes and traditions. From this standpoint, many a modern political unit, one of large cities for example, is a congeries of loosely associated societies rather than an inclusive and permeating community of action and thought. (MW9: 87-8)

At any given synchronic moment within a cultural matrix, there exist individuals and groups who share different associated relations and different habits and different social customs. Indeed, Dewey suggests, that the more complex a society's cultural matrix, the more likely it is to include individuals who possess habits that are informed by differing or even conflicting patterns of social customs (MW14: 90).

The ability of a society's cultural matrix to produce groups with different or even conflicting habits and social customs revealed for Dewey that morality, when taken as defining acceptable parameters 
of both individual behaviour and behaviour between individuals and groups within society, is also a socially determined activity. Whilst all humans form associations with and are formed by associations (habits/ social customs) with natural objects and other human beings within a cultural matrix, it is also the case that all human action has possible consequences for other natural objects and other human beings who share in association or who inhabit the same society:

Some activity proceeds from a man; then it sets up reaction in the surroundings. Others approve, disapprove, protest, encourage, share and resist... Conduct is always shared; this is the difference between it and a physiological process. It is not an ethical 'ought' that conduct should be social. It is social, whether bad or good. (MW14: 16)

Importantly, however, Dewey contends that what separates human associations from that of natural objects, such as assemblies of electrons, unions of trees, swarms of insects, herds of sheep or constellations of stars, is the ability of humanity to intelligently perceive, reflect upon and subsequently plan to secure certain consequences and avoid others (LW2: 243, 250, 257). This ability of humans to intelligently perceive the consequences of associated action is structured around two kinds of consequences: those that directly affect individuals engaged in a transaction of associated behaviour and those that indirectly affect individuals beyond those immediately concerned in the transaction.

Within this distinction, Dewey finds the germ of the distinction between conceptions of private and public transactions. Transactions where the consequences of action were confined, or thought to be predominantly confined, to those directly engaged in such associative behaviour are said to be private. Transactions where the consequences are perceived to be extensive, enduring and serious for persons beyond those immediately engaged in such transactions are said to be of a public disposition. However, Dewey refines his position further by stating that this distinction was ultimately drawn on the scope and extent to which consequences were deemed important by a society to warrant control, whether through inhibition or promotion. In essence, 
all private transactions of associative behaviour have the propensity to become public when they are perceived to have extensive, enduring and serious consequences for others beyond those directly engaged in them. As such, there is no domain of activities that is intrinsically private (LW2: 243-5, 252-3). ${ }^{9}$

It is within the distinction between private and public transactions that Dewey finds the key to the origins of the 'nature and office of the state', arguing that the perception of public transactions leads to emergence of what he calls a 'Public' and subsequently the founding of a state. In Dewey's sense of the term, a public comes into existence when persons, having become conscious of and sufficiently affected by the consequences of associative behaviour (habits) to deem it unacceptable, form a collective group or movement with a common interest in having such consequences systematically controlled or cared for (LW2: 245, cf. 52-3, 260). However, such a public faces a dilemma due to the fact that the very consequences that call forth a public expand beyond those directly engaged in such associative behaviour.

The regulation of such consequences cannot be conducted by the primary groupings involved in the respective associative behaviour in the first place (although self-organization by a group to regulate its activities is also an important phenomenon). Consequently, in organizing themselves to deal with such indirect consequences, such a public creates special agencies and appoints officials such as legislators, judges and executives (which might include members of a public acting as citizens) to regulate behaviour and protect (through laws, rights and establishment of practices) their interests. These officials and special agencies, argues Dewey, are what we nominally call government and help bring forth a state. However, as Dewey is at pains to point out, the state does not solely consist of the inaugurating of government or the rise of a public but rather it is the political organization of the public through government:

The lasting, extensive and serious consequences of associated activity bring into existence a public. In itself it is unorganised and formless. By means of officials and their special powers it becomes a state. A 
public articulated and operating through representative officers is a state; there is no state without a government, but also there is none without a public. (LW2: 277, cf. 245-57, 260)

The central premise of Dewey's conception of the state is its foregoing of any attempt to find the true nature or essence of the state in order to embrace an anti-essentialist view of the state. In this sense, Dewey argues that after the formation of a state through the political organization of a public, its functions (governmental practices, parameters and composition) are themselves prone to changing in character and tone due to the changing historical conditions of associative behaviour and the rise of new publics. In simple terms, Dewey argues that the state possesses a historical relativity of form and function rather than a static and enduring nature. ${ }^{10}$

The reason for this historical relativity of state form and function, Dewey suggests, involved the fact that the consequences of associative behaviour are linked to a society's cultural matrix and the historical propensity for the properties of a society's cultural matrix to change (Dewey, LW2: 263). A cultural matrix, Dewey contends, is itself always open and prone to change due to socio-economic and technological transformation, migration, exploration or wars that modify preexisting associations or create new associations (habits/customs) and consequences. At the same time, the very perception or meaning attached to the consequences of associated behaviour and the best methods to deal with such consequences can itself shift in terms of a change in intellectual habits. For instance, scientific discoveries or the emergence of a new political paradigm may radically alter how people approach the consequences of associated behaviour (LW2: 263-5, cf. 254-5, 278-9). On the back of this, Dewey stresses that change in a cultural matrix, what we can also call societal change, is a historical fact, which injects perpetual and potentially revolutionary change in multifarious and different marks of intensities across the various relations of associative behaviour within a society (LW11: 41). ${ }^{11}$

As such, Dewey's concept of a public does not denote a static and homogenous body of people but rather plural and ever-changing 
publics brought into existence in reaction to changes in a society's cultural matrix and the consequences of associated behaviour. ${ }^{12} \mathrm{On}$ a synchronic level, publics are plural, ranging in size, strength and interests due to the variety of associations, habits and social customs a cultural matrix puts into practice and the perceptions of consequences a cultural matrix provides (LW2: 254-5). For instance, if one considers issues such as animal rights, immigration, homosexuality, women's equality or welfare provision, it is clear that at any one moment in time there are potentially multiple publics with their own agendas and interests, who may or may not support another public's cause.

A person may belong to many different publics, based on how they are subjected to or perceive the consequences of associative behaviour. No two publics are therefore likely to ever have the same membership but a public may possibly possess members from other publics. In turn, because publics are differentiated by the associative behaviour invoked by the contours of material culture, publics may even be constructed in response to other publics. It is quite often the case, for example, that some publics hold interests and ideas of how the state could manage such interests, which other publics may find inherently unreasonable or even dangerous because they conflict with their own interests and values. Consequently, there is, Dewey stresses, often room for dispute or conflict between the interests of differing publics (LW2: 275, 354, cf. LW11: 56).

On a diachronic level, publics also come into existence and pass out of existence in response to the variety of associations a cultural matrix puts into practice and the perceptions of consequences a material culture provides. Publics may not only continue on from and modify the interests from where previous publics left off (e.g. religious/ socialist/feminist movements) but may be entirely original movements whose values and interests differ markedly from publics that precede them. All publics, however, emerge within a strategic context where the state and its institutions of government bear the hallmarks of the interests of previous publics. For example, new publics engendered by new conditions in material culture have often found that their inherited 
institutions, beliefs and traditions of government, which reflect the interests of older publics, suffer from a cultural 'lag' and are unfit to meet their needs (LW2: 255, cf. LW13: 97, LW11: 54, LW12: 82-3).

New publics will therefore often seek to modify the institutions and officials of government to suit their present interests and consequently modify the nature and functions of the state (LW2: 255). ${ }^{13}$ This may include fundamentally changing the nature and functions of a state as it has been laid down by previous publics, such as those that founded the state in the first place. In turn, the modification of the state's institutions of government, through changing the nature of associative behaviour and creating new forms of cultural norms and values, will affect and modify a society's cultural matrix and subsequently provide a new cultural matrix (consequences/perceptions of associative behaviour) for the possible emergence of future publics.

In the light of the perpetual propensity of a cultural matrix to change and call forth synchronically and diachronically differentiated publics, Dewey declares that the state is a historically relative entity whose functions were 'ever something to be scrutinized, investigated, and searched for' and hence remade and reorganized in reaction to the conditions of culture (LW2: 255). Dewey sums up his historicist view of the state by propounding that:

The consequences vary with concrete conditions; hence at one time and place a large measure of state activity may be indicated and at another time a policy of quiescence and laissez-faire. Just as publics and states vary with conditions of time and place, so do the concrete functions which should be carried on by states. There is no antecedent universal proposition which can be laid down because of which the functions of a state should be limited or should be expanded. Their scope is something to be critically and experimentally determined. (LW2: 281)

Concluding his examination of the state, Dewey argues that the philosophical preoccupation with an all-encompassing theory of the state's nature had always been a mirage of a goal in the first place. In provisional terms, whilst one could declare that the state was the 
political organization of the public via government and that such arrangements had certain historical traits of function, ultimately '.. what the public may be, what the officials are, how adequately they perform their function, are things we have to go to history to discover' (LW2: 253-6). ${ }^{14}$

\section{The history of publics and the spectre of violence}

The qualification that publics, government and consequently the state are historically relative properties based on the movements of a society's cultural matrix is the cornerstone of Dewey's recasting of the meaning of democracy and the justification for its practice vis-à-vis other forms of political settlement. This gambit involves Dewey initially reminding his readers that historical relativity of the state meant examining the formation of statehood and its evolution in the messy reality of human history. Detached from an appreciation of history, it is quite easy to read Dewey's theory of a state being based on a functional logic of publics emerging and progressively altering the institutions and practices of government in response to the changing conditions of culture.

In this schema, the state's evolution would resemble the progressive role set out for it in pluralist philosophy, whereby the state neutrally arbitrated and included the interests of differing publics, who have similar potential and resources for accessing and modifying the formation of government and state functions. Contra pluralism's vision of the state, however, Dewey pointed out that the very history that highlighted that states evolved via changes in the cultural matrix and the rise of publics also brought home the fact that such an evolution did not necessarily guarantee the 'propriety or reasonableness' of the publics or the political acts, measures or systems which emerged from such a process (LW2: 254).

For instance, Dewey highlights that the intellectual foundations (science/political ideologies) of a cultural matrix do not necessarily provide publics or governments with correct or just perceptions about 
associative behaviour. One has only to think about certain ideologies and subsequent government policies towards women, immigrants, non-whites or homosexuals over the eighteenth, nineteenth and twentieth centuries to see that the observation of the consequences of associated human behaviour is open to the same error and illusion as the perception of natural objects. The emergence of a public can also not be equated with an a priori expression of correctness or justness. As highlighted above, publics can emerge in response to other publics or often come into conflict with one another due to incompatible interests. This process itself can lead to the emergence of illiberal or unreasonable publics. Again, one has only to look to history to find how illiberal publics have shaped unjust state formations or even how what we today would call progressive publics, such as the ones that emerged to demand the abolition of New World Slavery and women's suffrage, were opposed by publics who demanded the status quo or even a heightening of illiberal practices. As a consequence, Dewey contends that mistaken prescriptions, based on such false observations or stemming from the wishes of illiberal publics, can consolidate themselves in laws and administrative policies of government creating retrogressive rather than progressive consequences (LW2: 254).

The historical evidence that culture could facilitate incorrect perceptions of associative behaviour or even invoke illiberal publics served to underline for Dewey that publics have rarely been of equal standing in a society. The historical relativity of the state's form revealed not only that other social groups precede the state, but that the state always exists as a 'distinctive and restricted social interest' - an agency whose form and functions are set up to meet the demands and protect the interests of specific publics within specific cultures at specific junctures in history (LW2: 253-4). For example, although states are brought into existence via the emergence of a public there are often other publics who are excluded from forming government in the very act of founding a state.

This process itself normally reflects socially stratified relations between groups within society at that juncture in history. And whilst 
the parameters of such social stratification may shift over time due to shifts in power, for example from heredity and lineage to economic class, the power and prestige of government is nearly always held in esteem by dominant groups. Thus, Dewey suggests that the primary task for any public is to achieve such recognition of itself across wider society to give weight to its attempts to modify government and associative behaviour in its interests (LW2: 283). The ability to gain access to the privileges of government has therefore often been distributed through birth into a dominant class, caste, race or gender rather than an ability to govern (LW2: 254, 283-4). ${ }^{15}$ This has created circumstances throughout history, where various publics and their interests have found themselves excluded, often unjustly and to their detriment, from the very process of the state being rediscovered and remade.

Moreover, Dewey suggests that well-institutionalized states and their incumbent governments, which reflect the interests and often contain members of previous publics, have historically hindered the process of the remaking of the state. This transpires because the needs of newly formed publics often challenge the moral values or interests of the previous public(s) that have shaped the present state and its government. Subsequently, well-institutionalized incumbent states and their governments have historically used the institutions and practice of government to counteract, discredit or suppress the rival interests of new publics. This expulsion of new publics from partaking in the remaking of the state and government has, Dewey contends, often been the catalyst for violent revolution:

The new public which is generated remains long inchoate, unorganized, because it cannot use inherited political agencies. The latter, if elaborate and well institutionalized, obstruct the organization of the new public. They prevent that development of new forms of the state which might grow up rapidly were social life more fluid, less precipitated into set political and legal molds. To form itself, the public has to break existing political forms. This is hard to do because these forms are themselves the regular means of instituting change. The public which generated political forms is passing away, but the power and the lust of 
possession remains in the hands of the officers and agencies which the dying publics instituted. This is why the change of the form of states is so often effected only by revolution. (LW2: 254-5)

What is of pertinence here is Dewey's belief that the historical relativity of culture and the emergence of new publics translate into a situation where a society is always in a process of transition and hence potential moral conflict. This conflict between the needs of old experience and of new experience, what we often refer to as social problems, is inherently a moral conflict because it concerns what should be within a society. Such conflicts, brought about by the events of a shifting cultural matrix, inherently question the values, principles and ends and corresponding social institutions (practices and institutions of government) that should exist at that specific historical juncture (LW13: 151, 184, cf. LW11: 36-7).

All societies, in some form, thus have to come face to face with the dilemma of integrating potentially conflicting moralities of old experience and new experience (Dewey, LW11: 36). However, as the prior notation of the historic propensity of violent revolution makes clear, striking the balance between (or even contemplating integrating the old and the new) has typically been beyond the political wit of humanity. Moreover, Dewey believed that the dilemma of integrating potentially conflicting moralities of old experience and new experience had led some into a belief in the necessity of violent coercive revolution (LW11: 41, 56-61, cf. LW14: 113). On this basis, Dewey concludes that the fundamental problem of political settlement in any society revolves around the question of how to manage social change and mediate potential moral conflict between the old and new experience without the necessity of coercive or violent politics. ${ }^{16}$

\section{Making the case for democracy as a way of life}

Rallying against democratic realism's caricature of democracy as merely being a set of defunct institutions, whose failings are only outweighed by the erroneous belief in their ability to succeed in the first place, 
Dewey puts forward democracy as the answer to the problem of how to manage societal change and mediate its potential moral conflicts without recourse to coercive or violent politics. In making such a statement, Dewey begins his attempt at deepening, clarifying and ultimately reconstructing the idea of democracy. Although acknowledging the embodiment of the concept in popular suffrage and elected officials, what we commonly call 'political democracy', Dewey contends that the idea of democracy must be separated from its external organs and structure. To reduce democracy to specific institutions or practices is quite simply to miss the fact that democracy is inherently something 'broader and deeper' than such institutions (LW2: 325, cf. LW11: 217 and LW7: 349). This broader and deeper meaning revolves around viewing democracy as the best method for establishing and maintaining a society's sense of community. And as we shall see, Dewey sees the establishment of community through democracy as paramount to peacefully managing moral conflict as it emerges throughout history (LW11: 56, 182, cf. LW7: 329). ${ }^{17}$

Dewey's reconstructed meaning of democracy is principally exemplified in his demarcation between democracy as a 'way of life' and 'political democracy' as a system of government (LW11: 217, cf. LW2: 325 and LW14: 226). The key to understanding Dewey's conception of democracy as a method for dealing with social change and moral conflict centres around viewing the former as providing the ethical mandate for the constant renewal of the institutions and practices of the latter (LW2: 325 , cf. LW11: 182, 218). In its simplest expression, democracy as a way of life represents for Dewey the expression of the democratic ideal or idea (LW7: 348-9, cf. LW2: 327). ${ }^{18}$ Underpinned by the Lincolnesque belief that no human is wise enough to rule others without their consent, democracy as a 'way of life' is premised on the necessity for the equal 'participation of every mature being in the formation of the values that regulate the living of men together' (LW11: 217-18, cf. LW13: 294).

The values in question here are the moral values (principles, ends) that justify and inform the social institutions (habits/customs/institutions of the cultural matrix) that influence how individuals both act and 
relate towards themselves and one another. Within these parameters, democracy as a way of life is best seen as an ethical commitment to the principle that those who are affected by social institutions should have a certain share in the production and management of those institutions through contributing to the formation of social policy (proposed reforms of social institutions). Dewey describes this ethical commitment as:

... the opportunity, the right and the duty of every individual to form some conviction and to express some conviction regarding his own place in the social order, and the relations of that social order to his own welfare; second, the fact that each individual counts as one and one only on an equality with others, so that the final social will comes about as the cooperative expression of the ideas of many people. (LW13: 295-6).

What is worth noting here is that such an ethical commitment operates on a balanced notion of an equality of participation and communication in the formation of social policy. On one hand, each individual or a group of like-minded individuals who have grouped together (publics) is taken to be equally affected in quality, if not in quantity, by the social institutions under which they live. All individuals or groups of likeminded individuals, regardless of any native (sex) or artificial (race, class, intelligence, political beliefs) endowments, should subsequently have the chance and opportunity to communicate their own conception of moral value. This fundamentally entails an equality of opportunity to express their own needs and desires, their conceptions of how social life should go on and how the social problems they perceive to exist can be solved via reforming social policy. In short, all individuals or groups should have an equality of opportunity to have their moral values solicited and potentially registered in social policy, so as to secure the social institutions that they believe will bring about the full development of their capacities as individuals (LW11: 219-20, cf. LW7: 349-50).

On the other hand, however, this equality of opportunity to contribute to the formation of social policy is balanced by the recognition of the 
aforementioned social nature of morality. As Dewey points out, '... capacity to endure publicity and communication is the test by which it is decided whether a pretended good is spurious or genuine. Communication, sharing, joint participation are the only actual ways of universalizing the moral law and end' (MW12: 197). The drive for the solicitation and registration of individual or group morality in social policy must always be refracted through the knowledge that such policy will affect and have consequences for 'other' individuals or groups within society, who in all likelihood, due to stratification and different interests engendered by the contours of culture, may share different or competing moral standpoints. The equality of opportunity to express moral value is therefore always used to facilitate the 'mutual conference and consultation' between those groups or individuals who hold differing or competing conceptions of moral value. The overall aim of such mutual conference and consultation is a form of collective problem-solving, where members of society cooperatively collaborate in the appraisal and forming of new social policy in regard to mediating moral conflicts. ${ }^{19}$

In essence, then, the balanced equality of democracy as a way of life and its focus on collective problem-solving highlights Dewey's faith in a deliberative (conference, consultation, negotiation and persuasion) form of political settlement - a process which, Dewey believed, would allow moral conflicts and the resultant social policy decisions to be settled in the 'widest possible contribution of all - or at least the great majority' (LW: 56). However, this deliberative form of political settlement is only able to deal competently with moral conflict both synchronically and diachronically, argues Dewey, because democracy as a way of life facilitates the establishment and maintenance of a society's community.

As detailed earlier, just as atoms, stellar masses and cells behave in the natural world, Dewey states that humans within a society directly and unconsciously combine in associated behaviour. Such associated behaviour needs no explanation or meaning; it is simply the way things are structured by culture. The attempt to provide explanation or meaning to associative behaviour and its consequences is for Dewey 
based on communication, whereby symbols or signs are produced about such associative behaviour and its consequences. The creation of symbols and signs or what we call a common language is thus exactly what publics do when they offer their narrations of associated behaviour and its consequences to wider society. The pivotal point here is that such a process, whereby explanation or meaning is given to associative behaviour and its consequences and then communicated to others, is for Dewey the move towards the establishment of community (LW13: 176).

A community thus represents an order of energies transmuted into one of meanings which are appreciated and mutually referred by each to every other on the part of those engaged in combined action. 'Force' is not eliminated but is transformed in uses and direction by ideas and sentiments made possible by means and symbols. (LW2: 331)

On this basis, Dewey takes the form of community invoked by democracy as a way of life, what we call the democratic community, to be the best means to deal with moral conflict and social problems on both synchronic and diachronic levels. Dewey's idea of the democratic community does not so much do away with moral conflict, which itself is an impossibility, but looks to mediate conflict and avoid violence through facilitating the communicative inclusion of all publics. This is quite simply because the ethical commitment of democracy as a way of life translates into the perpetual maintenance of a community, whereby everyone is afforded an equal opportunity to express moral value and potentially, through deliberation, have that moral value embodied in social policy.

On a synchronic level, as we have seen, due to stratification and the clash of interests that regularly occur between old and new publics, historically new publics have often been cut out of the process of remaking the state and have had to resort to violent revolution to achieve their objectives. Within the remit of the ethical commitment of democracy as a way of life, however, all individuals and groups possess the right to express their moral value. Dewey subsequently believed that the movement towards the necessity of violence to facilitate the 
changing of the state is largely eradicated under democracy as a way of life because such an ethical commitment aimed:

... to bring these conflicts out into the open where their special claims can be seen and appraised, and where they can be discussed and judged in the light of more inclusive interests than are represented by either of them separately... The more the respective claims of the two are publicly and scientifically weighed, the more likely it is that the public interest will be disclosed and be made effective. (LW11: 56)

The democratic way of life and its democratic community also shed light upon Dewey's hopes for a diachronic form of deliberative and cooperative problem-solving to mediate the moral conflicts which are 'bound to arise' in society (LW14:227-8). Under the tenets of democracy as a way of life, the problematic of facilitating the participation of every mature being in the formation of the values that inform a society's social institutions is never deemed to be permanently solvable, but rather considered a challenge whose demands change across time and space. This is because the ethical commitment that all members of a society will have the chance to voice their moral value and have the potential to inform social policy recognizes the historical relativity of culture and publics - a process where all forms of moral value espoused by new publics, across time and space, would always possess the right to be heard and be deliberated and, if sufficient evidence of its merit emerged, the chance of ultimately changing social policy (LW7: 350). At the heart of the democratic way of life and its sense of community thus beats an educative rhythm, which looks to ensure a perpetual equality of communication and co-operative problem-solving as social conditions and conceptions of moral value shift throughout history. ${ }^{20}$

\section{Democracy as a way of life + political democracy $=$ creative democracy}

The question that now remains, however, is how does Dewey's conception of democracy as a way of life relate to what we commonly 
call political democracy as a system of government? What should be clear from the preceding discussion is Dewey's belief that democracy as a way of life and its sense of community provides the respective ethical and deliberative foundations for the mediation of conflict via facilitating the co-operative reform and remaking of social institutions in response to changing contours of culture and the rise and fall of publics. The interesting point here is that Dewey conceives that democracy as a way of life is not just about political democracy but about the perpetual participation of every mature being in the formation of the values of the social institutions under which they live. As such, Dewey believes that the justification and purpose of the institutions and practices of political democracy are also bound to the democratic way of life.

On one hand, Dewey asserts that the institutions and practices of political democracy should always endeavour to further the pursuit of democracy as a way of life. This means that the institutions and practices of political democracy should endeavour to facilitate the evolution of other social institutions to mediate the changes in culture and conflict between old and new experience. To this end, Dewey contends that the institutions and practices that we commonly associate with political democracy, such as universal suffrage, recurring elections, responsibility of those who are in political power to the voters and the freedom of speech, inquiry and assembly, are the means which have been most expedient at various historical junctures towards the pursuit of the ethical commitment of democracy as a way of life and the upholding of a democratic community (LW11:218). This is because such institutions and practices of political democracy, through their commitment to equality of discussion, consultation and publicity, are premised on the uncovering and communicating of social needs and troubles and hence facilitate both the ethical mandate of democracy as a way of life and the collective solving of such problems (LW2: 364).

On the other hand, however, the institutions and practices of political democracy are themselves simply social institutions. They are not the final ends or values of democracy as a way of life but rather the mechanisms towards the 'effective operation' of the ideal (LW2: 325). 
Against the trend of what he saw as the quasi-religious idealization of political democracy's institutions and practices and other social institutions in general, Dewey argues that we must not see democracy as being 'fixed in its outwards manifestation' (LW11: 182). The institutions and practices of political democracy are not beyond criticism or innovation themselves and are to be appraised on how far they, and the consequences they produce, contribute to the effective operation of the democratic ideal (LW11: 218). For instance, the emergence of moral conflict and the pursuit of deliberatively solving such a problem may uncover that an institution or practice of political democracy is unfit or unsuited to meet the demands of facilitating the democratic way of life in the current contours of culture. Consequently, such defunct institutions and practices of political democracy, just like other social institutions, must be adapted or updated, through deliberative problem-solving, to meet the needs, problems and the conditions of the contemporary configuration of culture (LW11: 182, cf. LW13: 299).

The linkage between democracy as a way of life and political democracy brings home Dewey's conception of 'creative democracy.'. Creative democracy is simply shorthand for the working link between the democratic ideal and its outward manifestation in social institutions. For democracy as a way of life is not so much to be statically handed down across generations, argues Dewey, but rather to be inherited and creatively interpreted and enacted anew by each generation and its various publics in regard to their present:

The very idea of democracy, the meaning of democracy, must be continually explored afresh; it has to be constantly discovered, and rediscovered, remade and reorganized; while the political and economic institutions and social institutions in which it is embodied have to be remade and reorganized to meet the changes that are going on in the development of new needs on the part of human beings and the new resources for satisfying these needs. (LW11: 182)

Dewey concludes that creative democracy, where the democratic ideal is used to structure the evolution of social institutions through mediating 
the conflict of publics, was the only way to master the changes in social reality both that are already here and that are destined to come forth. Indeed, Dewey saw his approach to democracy as not only potentially radical and revolutionary, but also socially cohesive because of its refusal to ground violence and bloodshed as first principles in the act of being radical and revolutionary. To borrow the words of Dewey's friend and intellectual collaborator George Herbert Mead (1915), this conception of the democratic community was nothing short of the 'institutionalizing of revolution'. This is the sense in which Dewey (LW11: 296) suggests, contra its critics, that 'democracy is radical' and that the 'cure for the ills of democracy is more democracy' (LW2: 325).

Taking in his immediate context, Dewey warned that the choice between creative democracy and other forms of political settlement was stark. He argued that any attempt to merely stand still and not deal with an ever-shifting social reality and ever-changing publics - whether this be through an uncreative and static democracy, a Third Reich, communist utopia or reformulation of philosopher kings as experts would likely place humanity on the road to extinction. Moreover, as we shall explore in the next chapter, Dewey believed that creative democracy was needed not just within the nation state but beyond and between the nation states of the globe. This was because the violence of revolution had itself been revolutionized, whereby humanity now possessed the unprecedented ability to be the authors of its own collective destruction. 
John Narayan - 9781526101020

Downloaded from manchesterhive.com at 04/26/2023 11:26: $04 \mathrm{AM}$ 